\title{
The In-hospital Outcome of Ventricular Septal Defect Closure and Predictor of Morbidity and Mortality at Tertiary Level Cardiac Center
}

\author{
Navin Chandra Gautam ${ }^{1}$, Apurba Thakur ${ }^{1}$, Marisha Aryal ${ }^{1}$, Rupak Pradhan ${ }^{1}$, Dipesh Karki ${ }^{1}$, \\ Nishes Basnet $^{1}$, Yogeshwor Man Singh ${ }^{1}$, Rabindra Bhakta Timala ${ }^{1}$ \\ ${ }^{1}$ Department of Cardiovascular Surgery, Shahid Gangalal National Heart Center, Kathmandu, Nepal
}

Corresponding Author: Navin Chandra Gautam

Department of Cardiovascular Surgery, Shahid Gangalal National Heart Center, Kathmandu, Nepal

Email: navincg@hotmail.com

ORCID ID NO: 0000-0003-2416-4096

Cite this article as: Gautam N. C., Thakur A., Aryal M., et al. The In-hospital Outcome of Ventricular Septal Defect Closure and Predictor of Morbidity and Mortality at Tertiary Level Cardiac Center. Nepalese Heart Journal 2021; Vol 18(2), 39-43.

Submission date: 29 th August, 2021

Accepted date: 30 th September, 2021

Abstract

Background and Aims: Factors responsible for complications and outcomes of surgical closure of ventricular septal defect differ between different cardiac centers globally. In this study, we tried to evaluate outcomes and predictors of morbidity and mortality of surgical closure of VSD in a single center.

Methods: The retrospective cohort study was conducted in Shahid Gangalal National Heart Centre from 14th April 2018 to 13th April 2020. It included consecutive series of patients undergoing ventricular septal defect closure as a primary surgery

Results: Out of a total 166 patients, males were $100(60 \%)$. Adverse complications occurred on $36(21 \%)$ with mortality of 6 (3.6\%). The age ranged from 4 months to 35 years. The weight $<10 \mathrm{kgs}$ at the time of operation had significant post-operative prolong ventilation duration (more than 6 hours) with a $\mathrm{p}$ value of 0.012 ; significant prolong ICU stays ( $>2$ days) with a $p$ value of $<0.001$; significant prolong hospital stay ( $>7$ days) with a $p$ value of $<0.001$. The longer $\mathrm{CPB}$ time was associated with significantly prolonged ventilation duration ( $\mathrm{p}$ value 0.001 ); significant longer ICU stay ( $\mathrm{p}$ value 0.02 ). The age $<1$ year at the time of operation had significant prolonged ICU stay; significantly prolonged hospital stays ( $\mathrm{p}$ value of 0.033 ). Severe pulmonary artery hypertension $(\mathrm{PAH})$ and weight up to $10 \mathrm{kgs}$ at the time of operation demonstrated a trend towards association with mortality.

Conclusion: Surgical VSD closure can be done with acceptable level of mortality and morbidity in our context.

Keywords: Ventricular septal defect, outcome predictors, surgical closure.

DOI: https://doi.org/10.3126/njh.v18i2.40403

\section{Introduction}

Ventricular septal defect (VSD) is the most common cardiac anomaly in children and is the second most common congenital heart anomaly in adults, after the bicuspid aortic valve' ${ }^{1}$. Ventricular septal defect includes $40 \%$ of congenital heart diseases and occurs 0.34 to 2.68 per 1000 live births. ${ }^{2}$ Since the first successful repair of VSD was done by Lillehei and colleagues in 1957, surgical closure of VSD remains the most common pediatric cardiac procedure ${ }^{3,4}$.

The nature of complications and outcomes for ventricular septal defect repair differ between developed and developing countries ${ }^{5}$. Although, mortality and morbidity of surgical closure have reduced significantly in western countries; surgical outcome remains poor for patients in the younger age group and with low body weight at the time of surgery ${ }^{6,7,8}$. Studies published during the past decade had evaluated and analyzed risk factors and considered low body weight for children, associated conditions like severe pulmonary artery hypertension (PAH), syndromic children were causes for high morbidity and mortality of VSD closure 9 . In recent times, there are conflicting data regarding weight at the time of operation as risk factors for complications. Contemporary result of surgical VSD closure, published in 2017, was excellent with low morbidity and no mortality; low body weight has association with increased ventilation duration but does not have an association with adverse outcome $^{10}$.

VSD closure has been a regular surgery at our center since its inception. The surgical VSD closure constitutes $20 \%$ of all congenital heart surgery in our institute ${ }^{11}$. To our knowledge, the outcome, and factors affecting its outcome are not systematically 
evaluated yet in our context. We do not know either low body weight in children, age less than one year at the time of operation; an associated condition like severe pulmonary hypertension, patent ductus arteriosus, atrial septal defect or regurgitation of mitral, aortic and tricuspid valve and prolong bypass time and prolong aorticcross clamp time do have a significant role in the surgical outcome in our contest. With the introduction of device closure of VSD, present results of surgical closure are equally necessary to know for a current benchmark of treatment ${ }^{10}$. The purpose of this study is to assess both baseline characteristics, a risk factor for morbidity and mortality of VSD closure at Shahid Gangalal National Heart Center (SGNHC), Kathmandu, Nepal from 14th April 2018 to 13th April 2020 (two calendar years).

\section{Methods}

All patients who underwent surgical closure of VSD between 14th April, 2018 and 13th April 20, 2020 at Shahid Gangalal National heart Center, Department of cardiovascular surgery were retrospectively reviewed.

Isolated VSD and VSD with concomitant Atrial Septal Defect (ASD), Patent Ductus Arteriosus (PDA), Patent Foramen Ovalle (PFO), regurgitation of mitral, aortic and tricuspid valve who had undergone valve repair, valvular pulmonary stenosis was included in the study, where VSD closure was the main indication for the surgery. VSD with prior main pulmonary artery banding and prior coarctation of aorta repair were also included. All age groups were considered in the study population. Patients with VSD of other complex cardiac anomalies including Atrio-ventricular septal defect (AVSD), Tetralogy of Fallot (TOF), Double outlet right ventricle (DORV), Transposition of The Great Arteries (TGA), Truncus arteriosus (TA), post infarction VSD, and patients who had undergone VSD closure with valve replacement were excluded.

Hospital medical records of these patients were retrospectively reviewed with the permission of the hospital authority. After the clearance of the institutional review board of hospital, study was started. The Performa was created and data of patients meeting with the inclusion criteria were collected from operation theater record book, ICU record book, perfusion sheet and patient's files. The preoperative characteristics, echocardiography findings, age, sex, weight, concomitant lesion; operative findings like, the location of VSD, concomitant lesion and operation, aortic-cross clamp time, cardiopulmonary bypass time; post-operative ventilation duration in minutes, ICU stay in days, post-operative hospital stay in days, mortality and complications were examined. Outcomes were assessed throughout the hospital stay for operation. Ventilator support duration of less than 6 hours after the transfer to ICU were considered early extubation ${ }^{12}$. Intensive care unit (ICU) stay of more than 2 days and a hospital stay of more than 7 days considered prolong ICU stay and prolong hospital stay respectively. Indication for surgery was sorted out following standard guidelines. Echocardiography had been done by pediatric cardiologist of the institute. Severe PAH was considered by echocardiograph evaluation. The location of VSD was determined by intra operative findings and categorized into four categories: perimembranous, supracristal, inlet and muscular.

We examined the prevalence of the following adverse events: reintubation, transient heart block, need of permanent pacemaker, seizure, pneumonia, residual VSD, residual mitral regurgitation (MR), residual tricuspid regurgitation (TR), residual aortic regurgitation (AR), chylothorax, and death.

\section{Surgical Technique}

Median sternotomy was done in all patients. Cardiopulmonary bypass established with aortic and bi-caval cannulation. Cardioplegic cardiac arrest was achieved with del Nido or St Thomas cardioplegic solution according to the operative surgeon's preference. Ventricular septal defect was assessed and closed through right atriotomy in most of the cases. Only in few cases, VSD closed through the transaortic or transpulmonary approach, where it was appropriate. Polytetra Fluoroethylene (PTFE) patch using 5-0 prolene sutures mostly in continuous fashion were used for closure. Only in few cases, VSD was closed using interrupted sutures. Very few cases had undergone direct suture closure of VSD. Concomitant lesions like ASD closure, PDA ligation, PFO closure along with repair of mitral, aortic, tricuspid valve and pulmonary valvotomy were performed as indicated in the same setting. After the completion of all steps of surgery, patients were transferred to ICU under ventilator support.

\section{Statistical Analysis}

Statistical analysis was performed using IBM SPSS statistics (version 20.0.0). The Kolmogorov-Smirnov test was used to verify whether the data were normally distributed or not. Only birth weight and bypass time were normally distributed, all other continuous variables were non-normally distributed. The mean and standard deviation were used to describe normally distributed data, for not normally distributed data medians and ranges to describe the variables. Frequencies and percentages were used to describe categorical data. Univariate analysis was done using a univariate logistic regression model. Determinants that were univariately associated $(\mathrm{p}<0.1)$ with the outcome were included in a multivariate logistic regression model to verify whether they were independent predictors.

\section{Results}

There were 166 ventricular septal defects (VSD) closure patients who met the inclusion criteria during the study period. Patients' characteristics are presented in Table 1. Sixty percent of patients were male. The median age of the patient was $2(1-6)$ years and the median weight of the patient was $10(7-16.25) \mathrm{kgs}$. Fifty percent of the patients operated on were between the ages of 1 to 6 years. Twenty percent of the patients were within one year of age. The youngest patient operated on was of 4 months and the oldest patient was of 35 years. Forty eight percent of the patients were up to $10 \mathrm{kgs}$ at the time of operation.

Table1: Patient Characteristics

\begin{tabular}{|l|l|}
\hline \multicolumn{1}{|l|}{ Sex } & Frequency $(\%)$ \\
\hline $\begin{array}{l}\text { Male } \\
\text { Female }\end{array}$ & $100(60.2)$ \\
\hline Age & $66(39.8)$ \\
\hline$<1$ year (yrs) & $34(20.5)$ \\
\hline 1 - 6 years & $84(50.6)$ \\
\hline 6 years to 18 years & $42(25.3)$ \\
\hline 18 years and above & $6(3.6)$ \\
\hline Median Age (Yrs) & $2(1-6)$ \\
\hline Age range & 4 mon-35 yrs \\
\hline Wt. in Kgs & \\
\hline$<10$ & $81(48.8)$ \\
\hline $10+$ & $85(51.2)$ \\
\hline Median Weight (kgs) & $10(7-16.25)$ \\
\hline Range & $4.5-74$ \\
\hline Associate lesion: & \\
\hline Patent Foramen Ovale (PFO) & $40(24)$ \\
\hline Atrial Septal Defect (ASD) & $35(21.1)$ \\
\hline
\end{tabular}




\begin{tabular}{|l|c|}
\hline $\begin{array}{l}\text { Patent Ductus Arteriosus } \\
\text { (PDA) }\end{array}$ & $32(19.2)$ \\
\hline Pulmonary Stenosis (PS) & $4(2.4)$ \\
\hline $\begin{array}{l}\text { Mitral Regurgitation (MR) } \\
\text { Tricuspid Regurgitation (TR) }\end{array}$ & $30(18)$ \\
\hline $\begin{array}{l}\text { Aortic Regurgitation (AR) } \\
\text { Prior Coarctation of Aorta } \\
\text { (CoA) Repair }\end{array}$ & $6(3.6)$ \\
\hline $\begin{array}{l}\text { Prior Main Pulmonary Artery } \\
\text { (MPA) banding }\end{array}$ & $1(0.6)$ \\
\hline
\end{tabular}

Minimum of one associated lesion was present in $60 \%$ of patients. PFO associated with $40(24 \%)$, ASD associated with 35 (21.1\%), PDA associated with $32(19.2 \%)$. Fifty-six per cent of the patients were with severe pulmonary hypertension. One patient had coarctation of aorta repair before VSD closure. Pulmonary artery debanding and VSD closure had done with two patients. One patient had dislodged VSD closure device and subsequently underwent emergency retrieval of an embolized device with surgical closure

The operative and post-operative characteristics are presented in table 2. The most common VSD location was perimembranous $102(61.4 \%)$. The Second most common location of VSD was supracristal (sub arterial) 47 (28.3\%). Mean aortic cross-clamp time was $42.48+18.2$ minutes. Minimum AOX time was 18 min and max $128 \mathrm{~min}$. Early postoperative extubation (that is within 6 hours) was performed in $79.5 \%$ of patients. The postoperative ventilatory duration was a minimum of 70 minutes and a maximum of 481 hours (20 days). Fifty per cent of patients had stayed in ICU for up to 2 days. The minimum ICU stay was one day and a maximum of 39 days. Post-operative hospital stays a minimum of 3 days and a maximum of 49 days. Median postoperative ventilation duration, ICU stay, and hospital stays were 200 minutes, 2 days and 5 days respectively.

Table 2: Operative and post-operative characteristics $(\mathrm{n}=166)$

\begin{tabular}{|l|l|}
\hline Variables & Frequency \\
\hline CPB time & \\
\hline $\begin{array}{l}\text { less than mean CPB time with } \\
\text { more than mean CPB time with }\end{array}$ & $80(48.2 \%)$ \\
\hline $\begin{array}{l}\text { Mean duration (SD) in min } \\
\text { Min-Max CPB time in min }\end{array}$ & $67.69(24.50)$ \\
\hline Ventilation in HR & $33-170$ \\
\hline$<=6.00$ hours & $132(79.5 \%)$ \\
\hline$>6$ hours & $34(20.5 \%)$ \\
\hline Median (in min) & $200(150-300)$ \\
\hline Min-Max & 70 min-481 hours \\
\hline $\begin{array}{l}\text { post-operative ICU stay (in } \\
\text { days) }\end{array}$ & \\
\hline$<=2$ & $84(50.6 \%)$ \\
\hline$>2$ & $82(49.4 \%)$ \\
\hline $\begin{array}{l}\text { Median } \\
\text { Min-Max }\end{array}$ & $2(2-3)$ \\
\hline Post-op Hospital Stay (in days) & $1-39$ \\
\hline$<=7$ & $124(74.7 \%)$ \\
\hline$>7$ & $42(25.3 \%)$ \\
\hline Median & $5(4-8)$ \\
\hline Min-Max & $3-49$ \\
\hline & \\
\hline
\end{tabular}

A total of $36(22 \%)$ patients had a minimum of one complication. Eighteen $(11 \%)$ of patients had more than one complication. We examined the prevalence of the following adverse events: reintubation, transient heart block, need of permanent pacemaker, seizure, pneumonia, residual VSD, residual MR, residual TR, residual AR, chylothorax, and death. Multivariate regression analysis for the association of complication with patient's weight, age and CPB time was not done. Transient heart block was with $14(8.4 \%)$ patients. Four $(2.4 \%)$ patients received a permanent pacemaker for complete heart block before discharge. Diaphragmatic palsy occurred with one patient and had undergone diaphragmatic plication. Altogether there was $\operatorname{six}(3.6 \%)$ mortality.

Table 3: Complications

\begin{tabular}{|l|c|}
\hline \multicolumn{1}{|c|}{ Complication } & N (Percent) \\
\hline Reintubation & $12(7.2)$ \\
\hline Complete heart block & $4(2.4)$ \\
\hline needed of Pacemaker & $4(2.4)$ \\
\hline Transient heart block & $14(8.4)$ \\
\hline VSD residual Leakage & $9(5.4)$ \\
\hline residual TR & $6(3.6)$ \\
\hline Residual MR & $5(3)$ \\
\hline seizure & $5(3)$ \\
\hline Chylothorax & $1(0.6)$ \\
\hline Pneumonia & $7(4.2)$ \\
\hline Diaphragmatic Palsy & $1(0.6)$ \\
\hline Mortality & $6(3.6)$ \\
\hline
\end{tabular}

Weight less than $10 \mathrm{kgs}$ at the time of operation had significantly longer ventilation duration, significantly longer ICU stays, and significantly longer hospital stay. Likewise, longer cardiopulmonary bypass time had significantly longer ventilation duration and significantly longer ICU stays but doesn't have a relationship with a longer hospital stay. Age less than one year had significantly longer ICU stay and significantly longer hospital stay but there was no relationship with longer ventilation duration.

In this study, severe PAH and weight up to $10 \mathrm{kgs}$ at the time of operation demonstrated a trend towards association with mortality although not quite reaching statistical significance. Four patients died on the first post-operative day most likely due to severe pulmonary hypertensive crisis. Two patients died on 3rd and 4thPost due to low cardiac output syndrome, which may be due to poor myocardial protection during cardiac arrest.

Table 4: Multivariant analysis: risk factors for longer stay or ventilation time.

\begin{tabular}{|c|c|c|c|c|c|c|}
\hline & \multicolumn{2}{|c|}{$\begin{array}{c}\text { Post-op Hospital Stay } \\
(>7 \text { days })\end{array}$} & \multicolumn{2}{|c|}{$\begin{array}{l}\text { Post-op time at ICU } \\
>2 \text { days }\end{array}$} & \multicolumn{2}{|c|}{$\begin{array}{l}\text { Post-op Ventilation } \\
>6 \text { hours }\end{array}$} \\
\hline & OR $(95 \% \mathrm{CI})$ & $p$-value & OR $(95 \% \mathrm{CI})$ & $\mathrm{p}$-value & OR $(95 \% \mathrm{CI})$ & $\mathrm{p}$-value \\
\hline $\begin{array}{l}\text { Longer } \\
\text { CBP (more } \\
\text { than mean } \\
\text { Time) }\end{array}$ & $\begin{array}{c}1.016 \\
(0.501-2.062)\end{array}$ & 0.965 & $\begin{array}{c}2.083 \\
\left(1.1^{\prime} 21-3.87\right)\end{array}$ & 0.02 & $\begin{array}{c}4.103(1.655- \\
10.173)\end{array}$ & 0.001 \\
\hline $\begin{array}{l}\text { Weight at } \\
\text { operation } \\
<10 \mathrm{~kg}\end{array}$ & $\begin{array}{c}4.779(2.147- \\
10.636)\end{array}$ & $<0.001$ & $\begin{array}{c}4.544 \\
(2.366-8.729)\end{array}$ & $<0.001$ & $\begin{array}{l}2.242(1.068- \\
5.044)\end{array}$ & 0.047 \\
\hline $\begin{array}{l}\text { Age }(<1 \\
\text { years })\end{array}$ & $\begin{array}{c}2.11(1.92- \\
4.82)\end{array}$ & 0.033 & $\begin{array}{c}2.587 \\
(1.67-5.736)\end{array}$ & 0.019 & $\begin{array}{c}1.156(0.451- \\
2.964)\end{array}$ & 0.763 \\
\hline
\end{tabular}


Table 5: Relationship between pulmonary artery hypertension $(\mathrm{PAH})$, age and weight $(\mathrm{Wt})$ with mortality.

\begin{tabular}{|c|c|c|c|c|c|}
\hline & & \multicolumn{4}{|c|}{ Mortality } \\
\hline \multirow{3}{*}{ РАН } & & NO & YES & $\begin{array}{c}\text { OR } \\
(95 \% \mathrm{CI})\end{array}$ & p-value \\
\hline & $\begin{array}{l}\text { Mild/ } \\
\text { mod }\end{array}$ & $\begin{array}{c}72 \\
(98.6)\end{array}$ & $1(1.4)$ & $\begin{array}{c}4.09 \\
(0.47- \\
35.81)\end{array}$ & 0.525 \\
\hline & Severe & $\begin{array}{c}88 \\
(94.6)\end{array}$ & $5(5.4)$ & 1 & \\
\hline \multirow{2}{*}{$\begin{array}{l}\text { Age in } \\
\text { Years }\end{array}$} & $\begin{array}{l}<1 \\
\text { years }\end{array}$ & $\begin{array}{c}32 \\
(94.1)\end{array}$ & $2(5.9)$ & 1 & \multirow[b]{2}{*}{0.435} \\
\hline & $\begin{array}{l}1 \text { year } \\
\text { and } \\
\text { above }\end{array}$ & $\begin{array}{c}128 \\
(97.0)\end{array}$ & $4(3.0)$ & $\begin{array}{c}2.00 \\
(0.35- \\
11.41)\end{array}$ & \\
\hline \multirow{2}{*}{$\begin{array}{l}\text { Wt in } \\
\text { Kgs }\end{array}$} & $<10$ & $\begin{array}{c}76 \\
(93.8)\end{array}$ & $5(6.2)$ & 1 & \multirow[b]{2}{*}{0.123} \\
\hline & $10+$ & $\begin{array}{c}84 \\
(98.8)\end{array}$ & $1(1.2)$ & $\begin{array}{c}5.53 \\
(0.63- \\
48.37)\end{array}$ & \\
\hline
\end{tabular}

\section{Discussion}

This study evaluated outcomes of VSD closure surgery at a single institute, tertiary level cardiac center of Nepal. VSD closure is a relatively safe and expeditious procedure with low morbidity and mortality. Despite advances in surgery; preoperative co-morbidities, cardiopulmonary bypass, and post operative cardiac critical care all together plays major role in the outcome of the individual patient. Thus, it can be said that compounding factors for outcome depends upon the maturity of the institute and experiences of the individual member involved in the team.

In our study total number of patients were 166 where the male constitutes $60 \%$ and female constitute $40 \%$. Recent Study published from western countries reported more or less equal distribution of male and female population, Maartje et al., ${ }^{10}$ Anderson et al. ${ }^{8}$ Whereas, study published from our continent, the male dominant pattern is present ${ }^{13,14}$.

This is a current result of surgical closure at a tertiary level cardiac center in Nepal. Mortality was $3.6 \%$ which is comparable with the result of Southeast Asia (3.4\%)5 but higher than in developed countries. Surgical VSD closure mortality has been reduced to between $0.5-1.7 \%$ in western countries, which had fallen from $8 \%$ only two decades ago ${ }^{6,7}$. There are recent publications with zero post-operative hospital mortality from Netherland ${ }^{8}$.

The perimembranous vsd remains the most common location of vsd with $61 \%$ which is supported by many studies being most common in location ${ }^{5,6,7}$. Second most common location of VSD was supracristal with $28 \%$. The supracristal VSD account approximately $30 \%$ of VSDs in Asian's country, whereas in western countries it accounts for approximately 5-7 \% of VSDs closure ${ }^{15}$. Higher occurrence of the condition in our population has not been adequately explained, but it can be assumed that it is genetically determined

In our study complication rate was $22 \%$ which is comparable to a study published by Pakistani institute where the complication rate was $35 \%{ }^{5}$. Our rate of complication was high compare to the recent study from the Netherland $(15.6 \%)^{10}$ We had a transient heart block of $8.4 \%$, this is higher than the study published by Anderson et al $(3.5 \%)$ and Bushra et all $(2 \%)^{5,8}$. The need for a permanent pacemaker in this study was $2 \%$, which is comparable with Anderson et al (2.1\%),but higher than Bushra et al $(1 \%)^{5,8}$. Detection of immediate post-operative residual VSD was $9(5.4 \%)$ which is very low compare to study by Maartje et al. $(51 \%)^{10}$. In his study there was routine of doing echocardiography evaluation for every postoperative patient. We performed trans-thoracic echocardiography only in selective cases when the patient was hemodynamically unstable and had undergone concomitant aortic or mitral valve repair. Our number of residual leakages is not reliable until we routinely do the echocardiographic evaluation of all postoperative patients. Pneumonia compromises $7 \%$ of complication which is comparable with the study published from the Indian subcontinent.

In our study, VSD was associated with PFO, ASD, PDA, PS, and MR among 40 (24\%), 35 (21.1\%), 32 (19.2\%), 4 (2.4\%) and $30(18 \%)$ population respectively. Association with PDA had shown prolong ICU stay and hospital stay. The relationships of complication with associated lesions were not evaluated due to the small sub group. A Study done by Knott-Craig et al had identified VSD associated with ASD as an important risk factor for surgical outcome of VSD closure ${ }^{16}$.

The current study concluded that low body weight at operation is associated with longer postoperative ventilation duration and longer post-operative ICU stay. This finding is supported by a study published by Anderson et al. and Aydemir et al ${ }^{8,17}$ but denied by publication done by Kogon et al. stating that bodyweight does not influence these aspects?

This study showed that severe PAH and weight up to $10 \mathrm{kgs}$ at the time of operation demonstrated a trend towards association with mortality although not quite reaching statistical significance. The age up to one year doesn't have association with mortality. Several studies have shown that the association between severe PAH and higher mortality and morbidity in patients undergoing VSD repair $^{10,14}$

\section{Limitation}

There are several limitations to this study. First of all, this is a retrospective study that depended upon the written documentation of several healthcare personnel. Second, over the study period, seven surgeons with different teams were involved in the surgery and post-operative care of the patient. The size of the VSD could not be categorized according to the size of the aortic root. Cardiac catheterization was done only with selective cases of severe PAH. The finding of their report was not evaluated in this article. There is no definitive protocol in postoperative care of the patient in our institute. Almost all of the patients were extubated as early as possible, but ICU stay and hospital stay were very much subjective without any definite protocol. Post-operative management in the center is different among the different teams. Prolong ICU stay ( $>2$ days) and prolong hospital stay ( $>7$ days) were defined arbitrarily. Risk Adjusted Classification for Congenital Heart Surgery (RACHS-1) levels was not evaluated as risk factors for complications. This is a single institutional review that might not be applied to another institute.

\section{Conclusion}

Low body weight will prolong ventilation duration, ICU stays, and eventually hospital stay. There was a trend toward association of severe PAH and low body weight at the time of operation with surgical mortality but there is no significant relation. Likewise, age up to 1 year at the time of operation was associated with prolong ICU stay and hospital stay but do not have any significant association with mortality. Therefore, surgical VSD closure is considered a safe procedure regardless of their age but low weight at the time of operation and severe pulmonary hypertension may be considered a risk factor as a trend toward mortality in our context.

\section{Conflict of interest}

None

\section{Source of fund}

None. 


\section{References}

1. Dakkak W, Oliver TI, Ventricular Septal Defect. StatPearls Publishing. 2020 June 7; http://www.ncbi.nih.gov/books/ NBK470330/

2. Lillehei CW, Varco RL, Cohen M, et al. The first open-heart repairs of ventricular septal defect, atrioventricular communis, and tetralogy of Fallot using extracorporeal circulation: a 30year follow-up. Ann Thorac Surg. 1986; 41:4-21. https://doi.org/10.1016/S0003-4975(10)64489-X.

3. Mirzaaghayan M R, Mog, Moghadam E A, Dehestani Alireza, Ghamari A. Early surgical closure of the ventricular septal defects; to be done or not to be done? A question to be answered. Iran J Pediatr. 2018 December; 28(6): e58876. https://doi.org/ 10.5812/ijp.58876.

4. Starling GR, Stanley PH, Lillehei CW. The effects of cardiac bypass and ventriculotomy upon right ventricular function; with report of successful closure of ventricular septal defect by use of atriotomy. Surg Forum. 1957; 8:433-8. PMID: 13529648

5. Bushar O, Muneer AM, Mehnaz A. Surgical outcomes of pediatric patients with ventricular septal defect in a tertiary referral center in Pakistan: A retrospective cohort study. J Clin Exp Cardiology. 2013,4:10. https://doi.org/10.4172/21559880.1000269

6. Scully B B, Morales D L, Zafar F, Mckenzie E D, Fraser C D Jr, et al. (2010) Current expectations for surgical repair of isolated ventricular septal defects. Ann Thorac Surg 89: 544-549.PMID: 20103339. https://doi.org/ 10.1016/j. athoracsur.2009.10.057

7. Nygen A, Sunnegardh J, Berggren H. Preoperative evaluation and surgery in isolated ventricular septal defects: 21 years perspective. Heart 2000 Feb; 83(2): 198-204.doi: 10.1136/ heart.83.2.198. PMID: 10648497; PMCID: PMC1729305. https://doi.org/10.1136/heart.83.2.198

8. Anderson B R, Stevens K N, Nicolson S C, Gruber S B, Spray TL. et al. (2013) Contemporary outcome of surgical ventricular septal defect closure. J Pediatr 140: 736-741. PMID: 23414985. https://dx.doi.org/ 10.1016/j. jtcvs.2012.11.032

9. Kogon B, Butler H, Kirshbom P et al. Closure of symptomatic ventricular septal defects: how early is too early? Pediatr Cardiol. 2008; 29(1): 36-9. PMID: 17676370 https://doi.org/ 10.1007/s00246-007-9016-Z

10. Maartje S, Martijn G S, Paul H S, Johannes M P J Breur. Surgical Repair of Ventricular Septal Defect; Contemporary Results and Risk Factors for a Complicated Course. Pediatr Cardiol. 2017;38(2):264-270. https://doi.org/10.1007/s00246016-1508-2.

11. Gautam N C, Timila R B, Pradhan S, et al.The Spectrum of congenital heart diseases operated at Shahid Gangalal National Heart Center in the last five year. Nepalese heart Journal 2021; Vol 18(1): 13-17. Doi: https://orchid.org/10.3126/njh. v18il.36770.

12. Davy C. H. Cheng; Fast Track Cardiac Surgery Pathways: Early Extubation, Process of Care, and Cost Containment. Anesthesiology 1998; 88:1429-1433 doi: https://doi. org/10.1097/00000542-199806000-00002

13. Saleem K, Sultan M, Sadiq N. Surgical closure of ventricular septal defect- experience at Armed Forces Institute of Cardiology. Pak Armed Forces Med J 2014; 1(1): S100-104
14. Mehamood A, Ahmed A, Ahmed W. Outcome of surgery of congenital heart disease at AFIC/NIHD. Rawalpindi Pakistan in 2000. Pak J Cardiol 12:67-71.

15. McDaniel NL, Gutgesell HP. Ventricular septal defects. In: Allen HD, Driscoll DJ, Shaddy RE, Feltes TF, eds. Moss and Adams' Heart Disease in Infants, Children, and Adolescents. 7thed. Philadelphia: Wolters Kluwer/ Lippincott Williams \& Wilkins; 2008. 667-82.

16. Knott-Craig C J, Elkins R C, Ramakrishan K, Hartnett D A, Lane M M, et al. Associated atrial septal defects increase perioperative morbidity after ventricular septal defect repair in infancy. Ann Thorac Surg.1995; 59: 573-578.PMID: 7887692 https://doi.org/ 10.1016/0003-4975(94)01005-6

17. Aydemir N A, Harmandar B, karaci A R, Sasmazel A, Bolukcu A, etal. Results for surgical closure of isolated ventricular septal defects in patients under one year of age. J Caed Surg 2013; 28(2): 174-179. https://doi.org/ 10.1111/jocs.12073. 